\title{
A pH-sensitive EVAL membrane by blending with PAA
}

\author{
Ping-Shan Lai, Ming-Jium Shieh, Chin-Ling Pai, Cheng-Yi Wang, Tai-Horng Young* \\ Institute of Biomedical Engineering, College of Medicine and College of Engineering, National Taiwan University, Taipei 10016, Taiwan, ROC \\ Received 15 April 2005; received in revised form 2 September 2005; accepted 7 September 2005 \\ Available online 19 October 2005
}

\begin{abstract}
The purpose of this study was to produce pH-sensitive domain in the dense poly(ethylene-co-vinyl-alcohol) (EVAL) membrane for colonic delivery of anti-cancer drug 5-fluorouracil (5-FU) by blending with a small amount of poly(acrylic acid) (PAA). The Fourier transform infrared (FTIR) spectroscopy analysis shows that PAA and EVAL were not very compatible in the PAA/EVAL blended membrane, whereas the intensity of self-association of both polymers was higher than that of inter-association between PAA and EVAL. It was proposed that PAA molecules would aggregate to act as the access for the transport of 5-FU through the blended membranes. The aggregated PAA gel phases were beyond the observable sensitivity of the scanning electron microscopy (SEM) and were low permeable for 5-FU at low pH, but significantly improved the permeability of 5-FU by the increase of $\mathrm{pH}$ of the medium, which agreed with the application of colon-specific drug delivery. When the membrane preparation temperature was changed from 60 to $45^{\circ} \mathrm{C}$, PAA domain contained in the blended membrane did not affect the permeation rate of 5-FU at different $\mathrm{pH}$. This is because the membrane prepared at $45^{\circ} \mathrm{C}$ was not so dense as that prepared at $60{ }^{\circ} \mathrm{C}$. Therefore, the $\mathrm{pH}$-sensitive characteristic of PAA domains would be applicable only to the membrane with a dense structure. Finally, it was demonstrated that 5-FU separated by the blended membranes still exhibited cytotoxicitiy toward Caco-2 cells at $\mathrm{pH}$ 7.4. Thus, the PAA/EVAL blended membrane is a potential material for the specific delivery of 5-FU to the colon for local treatment of colorectal cancer in the future clinical application.
\end{abstract}

(C) 2005 Elsevier B.V. All rights reserved.

Keywords: EVAL; PAA; Blending; pH-sensitive

\section{Introduction}

Colorectal cancer $(\mathrm{CRC})$ is one of the most common malignancies in industrialized countries. Mortality of CRC is attributable to metastatic disease that occurs most often in the liver, followed by the lung. 5-Fluorouracil (5-FU) is one of the most widely used agents in the first-line chemotherapy of CRC [1-4], but produces severfe hematological, mucosal and gastrointestinal toxicity, which is often encountered with dose intensification strategies and with moderate doses in adjuvant therapy treatment [5].

An understanding of 5-FU mechanisms of action has resulted in major therapeutic advances during the past decade; however, a plateau has been reached in the efficacy of 5-FU [6]. Maximizing therapeutic response by increasing selectivity is a major goal in the development of anticancer therapy. It would be highly beneficial to target 5-FU to a particular site within the gastroin-

\footnotetext{
* Corresponding author. Tel.: +8862 23123456x 1444; fax: +8862 23940049.

E-mail address: thyoung@ha.mc.ntu.edu.tw (T.-H. Young).
}

testinal tract, either to maximize a therapeutic response or to reduce side effects caused by drug delivery to an inopportune region of the gut. The development of oral administration of 5-FU derivatives is one vigorously pursued direction without incomplete and unpredictable absorption due to its degradation in the gastrointestinal tract [7].

Within recent years, the development of drug delivery systems capable of selective release of drug in the colon has received much attention [8-10]. The optimum oral drug delivery system in such a case requires technologies that protect the drug through the "acidic" stomach and then distribute the drug to act topically in the "neutral" colon. Hydrogels have been used widely for the preparation of drug delivery systems with physically or chemically modulated responses. Generally, the $\mathrm{pH}$-sensitive hydrogels are based on anionic polymers such as acrylic or methacrylic acids, which are water-impermeable at low $\mathrm{pH}$, but the water can freely enter the swollen gel to act as a transport agent for drug by the change of $\mathrm{pH}$ of the medium [11-16].

Clinically, poly(ethylene-co-vinyl-alcohol) (EVAL) was used in hemodialysis with appropriate biocompatibility [17]. In our laboratories, EVAL membranes have been studied inten- 
sively over the past 10 years for different biomedical applications such as plasma protein separation [18], drug delivery [15,19] and neuron cell culture [20-22]. In the present work, poly(acrylic acid) (PAA)/EVAL blended membranes were prepared by the dry-cast process from mixed polymer solutions in a common solvent [23] and the permeation of 5-FU through the membranes were investigated at $\mathrm{pH} 2.0$ and 7.4 for the development of $\mathrm{pH}$-sensitive membranes. The present study is concerned with investigation of blends of EVAL with PAA in different ratios and prepared at different solvent evaporation temperature. The properties of PAA/EVAL blended membranes were investigated by scanning electron microscopy (SEM), Fourier transform infrared (FTIR) spectroscopy and water swelling analysis. We demonstrated that the PAA/EVAL blended membrane with $3.3 \mathrm{wt} . \%$ of PAA prepared at $60^{\circ} \mathrm{C}$ was a potential material to reach a goal of releasing 5-FU for local treatment of CRC in the future clinical application.

\section{Materials and methods}

\subsection{Materials}

EVAL (E105A, containing ca. $56 \mathrm{~mol} \%$ vinyl alcohol) was kindly supplied by Kuraray (Japan) and used as received. PAA used in this study was purchased from Aldrich (USA) and it has a quoted molecular weight of viscosity $\left(M_{\mathrm{V}}\right)$ of 750,000 and $T_{\mathrm{g}}$ of $106^{\circ} \mathrm{C}$. Ethanol was purchased from Showa (Japan). Water was double distilled and deionized before use. 5-FU was purchased from Sigma (USA) and used as the model drug for colon-specific delivery.

\subsection{Membrane preparation}

PAA and EVAL were dissolved in a cosolvent containing $40 \mathrm{vol} . \%$ water and $60 \mathrm{vol} . \%$ ethanol [23] to form 2 and $15 \mathrm{wt} . \%$ polymer solutions at $60{ }^{\circ} \mathrm{C}$, respectively. The two solutions were mixed together in different ratios to give clear homogeneous PAA/EVAL blended solutions. The blended solutions were dispersed uniformly on Teflon plates (ca. $120 \mu \mathrm{m}$ ) at $60^{\circ} \mathrm{C}$, and then were immediately placed in an air-circulated oven at 60 or $45^{\circ} \mathrm{C}$ until the casting solution became the solid membranes. Subsequently, the membranes were removed from the Teflon plate and dried in vacuum for $24 \mathrm{~h}$. PAA/EVAL blended membranes were prepared with four different ratios as listed in Table 1. These membranes with the same composition such as ' $\mathrm{P}-1$ ' were named as $\mathrm{P}-1-60 \mathrm{C}$ and $\mathrm{P}-1-45 \mathrm{C}$ according to the membrane preparation temperature 60 and $45^{\circ} \mathrm{C}$, respectively. The thickness of the membrane was $15 \pm 1 \mu \mathrm{m}$. The freeze-dried

Table 1

The composition of PAA/EVAL blended membranes

\begin{tabular}{ll}
\hline No. of PAA/EVAL blended membrane & PAA/EVAL (wt.\%) \\
\hline P-1-60C, P-1-45C & $0 / 100$ \\
P-2-60C, P-2-45C & $1.5 / 98.5$ \\
P-3-60C, P-3-45C & $2.3 / 97.7$ \\
P-4-60C, P-4-45C & $3.3 / 96.7$ \\
\hline
\end{tabular}

membranes were gold coated and viewed with a SEM (S-800, Hitachi, Japan) at $20 \mathrm{kV}$.

\subsection{FTIR spectroscopy}

The PAA/EVAL blended membranes were analyzed by FTIR spectroscopy employing a Bio-Rad FTX3000 spectrophotometer to investigate intermolecular interactions between PAA and EVAL in the blended membranes. All spectra were obtained at room temperature with a nominal resolution of $4 \mathrm{~cm}^{-1}$ and were signal averaged over 64 scans.

\subsection{Swelling behavior of the membrane}

A piece of a known weight membrane was immersed in buffered solution at $\mathrm{pH} 2-6$ and 7.4 at $37^{\circ} \mathrm{C}$. The swelling was followed and then the swollen membrane was removed from the buffer solution and weighed after the superfluous liquid was carefully wiped with tissue paper. The swelling equilibrium was established until no further weight increase was observed. The swelling ratio $\left(S_{\mathrm{w}}\right)$ was determined according to the following expression:

$S_{\mathrm{W}}=\frac{W_{\mathrm{s}}-W_{\mathrm{d}}}{W_{\mathrm{d}}}$

where $W_{\mathrm{s}}$ is the weight of the swollen membrane and $W_{\mathrm{d}}$ is the weight of the dried membrane. All the data were averages of three independent experiments.

\subsection{5-FU permeation across the membrane}

Permeation by diffusion of 5-FU through the prepared membranes was studied at $\mathrm{pH} 2.0$ and 7.4 at $37^{\circ} \mathrm{C}$ with 5-FU concentration of $50 \mu \mathrm{g} / \mathrm{ml}$. The permeation experiments were carried out using a two-chamber diffusion cell with a volume of $40 \mathrm{ml}$ each. The membranes with an effective permeation area equal to $5.3 \mathrm{~cm}^{2}$ were clipped between the chambers. Vigorous agitation ca. $600 \mathrm{rpm}$ was employed using independently controlled magnetic stirrers for both chambers. Since the permeability measurement was performed under sufficient stirring, the diffusion resistance at the liquid-membrane interface was neglected [24].

One of the diffusion chambers was filled with buffer solution containing 5-FU as the donor side and the other chamber was filled with buffer solution only as the receptor side. The permeability of 5-FU through the prepared membrane was monitored by periodically removing $200 \mu \mathrm{l}$ samples from the receptor side and refilled back to avoid errors arising from the resulting volume variation. The concentrations of 5-FU were analyzed by an UV spectrophotometer (Ultrospec 1000E, Pharmacia Biotech, Sweden) from the peak absorbance at $266 \mathrm{~nm}$. Each experiment was repeated three times and the results were expressed as the mean of the three results.

\subsection{Viability of Caco-2 cells}

In vitro test was carried out to test the viability of human colon cancer cell line, Caco- 2 cells, exposed to 5 -FU but separated 


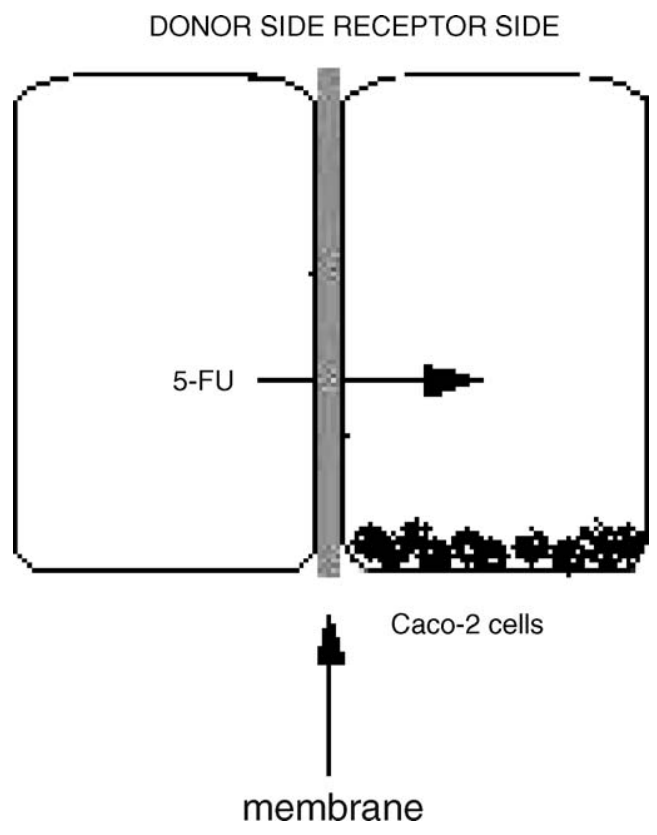

Fig. 1. A schematic diagram of 5-FU permeation experiment combined with cell culture in a two-chamber diffusion cell.

by the prepared membranes in the diffusion cell as described above. Caco-2 cells were obtained from the American Type Culture Collection (Rockville, MD, USA). One of the diffusion chamber was filled with minimum essential medium (MEM) containing 20\% fetal bovine serum (FBS, Gibco BRL Life Technologies, Paisley, UK) and 5-FU at pH 7.4 and the other chamber was filled with MEM containing $20 \%$ FBS, antibiotic/antimycotic (penicillin $\mathrm{G}$ sodium $100 \mathrm{U} / \mathrm{ml}$, streptomycin $100 \mathrm{mg} / \mathrm{ml}$, amphotericin B $0.25 \mathrm{mg} / \mathrm{ml}$, Gibco BRL Life Technologies) and Caco-2 cells cultured as a monolayer at $\mathrm{pH}$ 7.4, as shown in Fig. 1. The viability of Caco-2 cells was evaluated by cellular ability to reduce 3-(4,5-dimethylthiazol-2-yl)-2,5diphenyl tetrazolium bromide (MTT, M-2128, Sigma, St. Louis, MO, USA) [25] after the 5-FU permeation for $24 \mathrm{~h}$ at $37^{\circ} \mathrm{C}$. Since mitochondrial dehydrogenases of viable cells cleave selectively to the tetrazolium ring, yielding blue/purple formazan crystals, the level of the reduction of MTT into formazan can reflect the level of cell viability. For the MTT assay, the culture medium was removed, and then cells were incubated with $0.1 \mathrm{ml}$ of MTT $\left(2 \mathrm{mg} / \mathrm{ml}\right.$ in PBS) for $3 \mathrm{~h}$ at $37^{\circ} \mathrm{C}$. After incubation, the medium was aspirated and the formazan reaction products were dissolved by dimethyl sulfoxide (Aldrich, Milwaukee, WI, USA) in PBS and shaken for $15 \mathrm{~min}$. The optical density of the formazan solution was read on an ELISA plate reader (ELx 800, BIO-TEK, Winooski, VT, USA) at $570 \mathrm{~nm}$. Cell viability determined by the MTT assay was expressed as percentage of control Caco-2 cells without adding 5-FU into the diffusion chamber.

\section{Results and discussion}

\subsection{Membrane morphology}

Macroscopically, EVAL and PAA/EVAL blended membranes prepared at 60 and $45^{\circ} \mathrm{C}$ appeared colorless transparent.

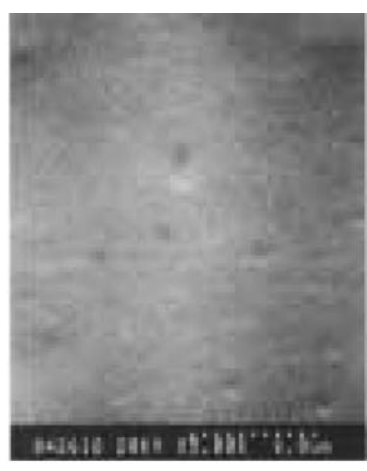

(a)

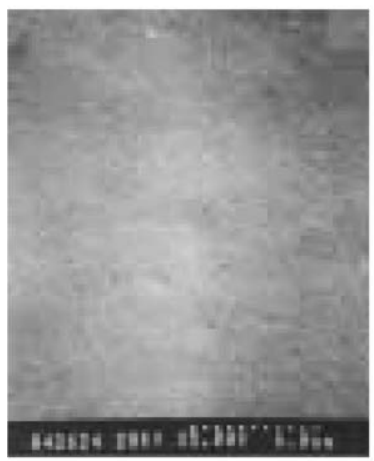

(b)

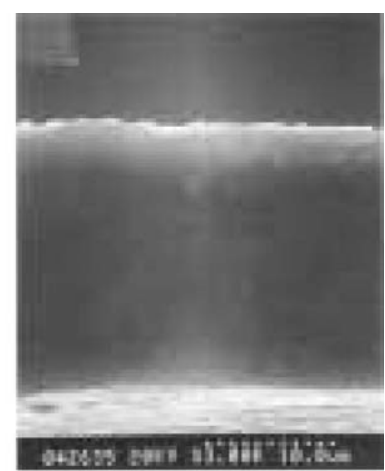

cross-section

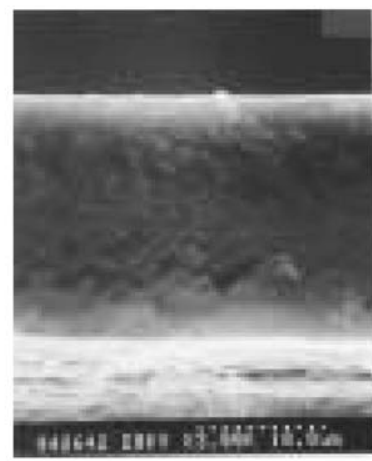

cross-section
Fig. 2. The SEM photomicrographs of top surface and cross-section of: (a) P1-60C and (b) P-1-45C membranes.

Microscopically, EVAL membranes prepared at 60 and $45^{\circ} \mathrm{C}$ showed slight difference, as indicated in Fig. 2. The EVAL membrane prepared at $60^{\circ} \mathrm{C}(\mathrm{P}-1-60)$ appeared fairly dense structure in top surface and cross-section. The microscopic analysis of the membrane prepared at $45^{\circ} \mathrm{C}(\mathrm{P}-1-45)$ also showed no holes existing in the membrane surface, but its cross-section was not so dense as that of P-1-60 membrane. After EVAL blended with PAA, the blended membranes (P-2, P-3 and P-4) showed similar dense morphology to the pure EVAL membrane, regardless of membrane preparation temperature (not shown here). Thus, the blending processes did not change the membrane structure under the observable detection sensitivity of the SEM.

\subsection{Interaction between PAA and EVAL in the blended membranes}

To investigate the interaction between PAA and EVAL in the blended membranes, samples were analyzed by IR absorption spectroscopy. Fig. 3 shows the FTIR spectra in the $3000-3800 \mathrm{~cm}^{-1}$ region for the hydroxyl-stretching band of EVAL and PAA/EVAL blended membranes. This broad band is known to consist of contributions from hydroxyl groups surrounded by different environments: hydroxyl groups hydrogenbonded with other hydroxyl groups in the same or different chains and non-hydrogen-bonded hydroxyl groups [26]. When the spectra of EVAL membrane was compared, the maximum of this band of the PAA/EVAL blended membranes shows a progressive shift from 3348 to $3358 \mathrm{~cm}^{-1}$ as the PAA con- 


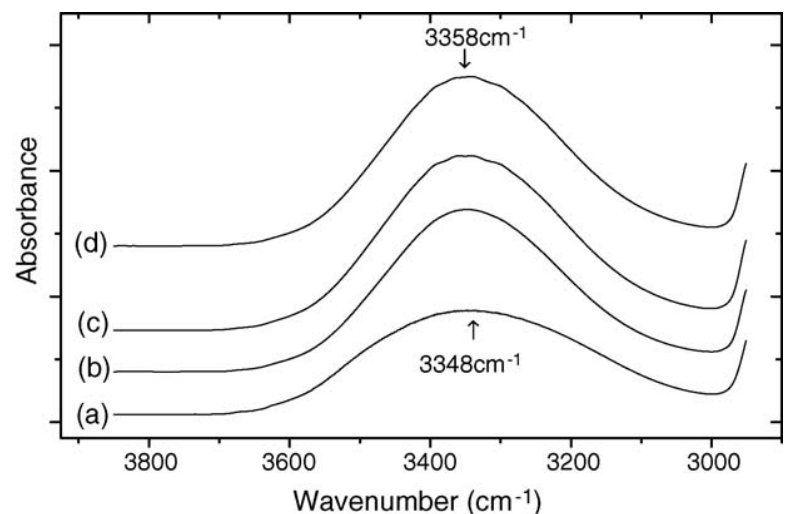

Fig. 3. FTIR spectra of the hydroxyl stretching region of: (a) P-1-60C, (b) P-2$60 \mathrm{C}$, (c) P-3-60C and (d) P-4-60C membranes.

tent increased. This result suggests that a redistribution in the arrangement of the hydroxyl group associations of the EVAL, which either are involved in the association processes for pure EVAL or hydrogen-bonded to the hydroxyl groups in PAA. The shift toward a higher wave number side indicates that the intensity of the inter-association between PAA and EVAL in the blended membranes was lower than that of self-association in the pure EVAL membrane.

The FTIR spectra in the carbonyl stretching region for the EVAL and PAA/EVAL blended membranes are shown in Fig. 4. As the PAA was blended with EVAL, the carbonyl absorption band at around $1716.6 \mathrm{~cm}^{-1}$ appeared. The intensity of this band increased upon increasing PAA content in the blended membranes. The carbonyl absorption band of pure PAA is at $1711 \mathrm{~cm}^{-1}$ [27]. Since the PAA carbonyl group could be hydrogen-bonded to the EVAL hydroxyl group or the PAA carboxyl group, the absorption band shifting to a higher wave number side indicated that the hydrogen bonding between PAA and EVAL was relatively weak than that in pure PAA.

Based on Figs. 3 and 4, the interaction of hydrogen bonding between PAA and EVAL declined the intensity of selfassociation in pure PAA or in pure EVAL, but the intensity of self-association of both polymers was still higher than that of inter-association between PAA and EVAL. Therefore, PAA

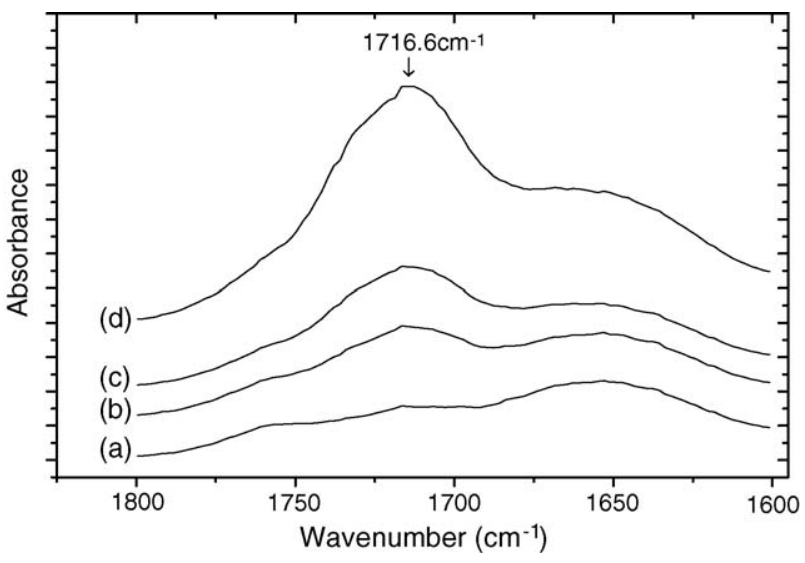

Fig. 4. FTIR spectra of the carbonyl stretching region of: (a) P-1-60C, (b) P-260C, (c) P-3-60C and (d) P-4-60C membranes.

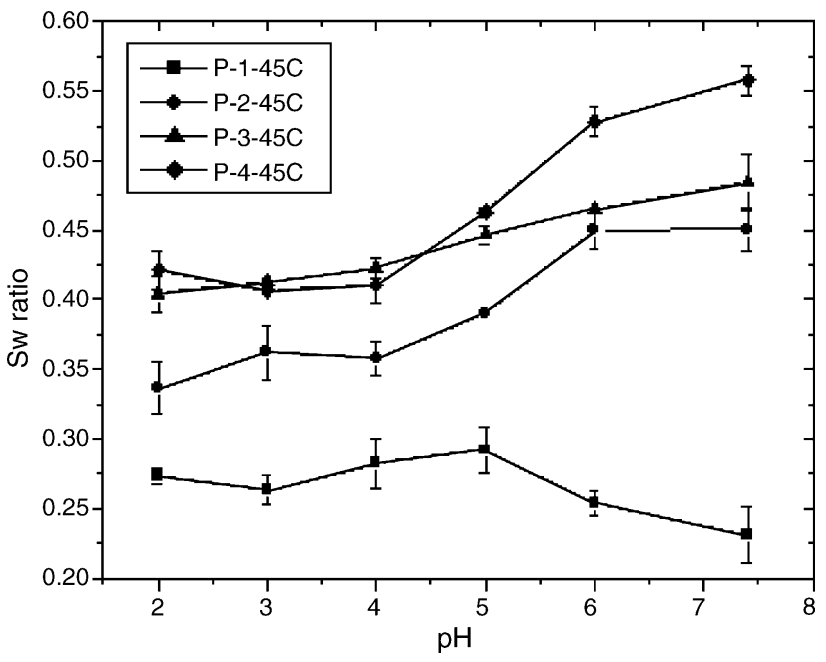

Fig. 5. Swelling ratio of EVAL and PAA/EVAL blended membranes prepared at $45^{\circ} \mathrm{C}$ in buffer solutions with different $\mathrm{pH}$ values at $37^{\circ} \mathrm{C}$.

could be added into the EVAL membranes, but PAA and EVAL were not very compatible in the blended membrane. Actually, as the PAA content exceeded about $6 \%$, the blended solution became so turbid that a homogeneous solution became mechanically impractical. For this reason, it is reasonable to assume that PAA molecules could segregate into distinct phases in the blended membranes. Although such modification by blending with a small amount of PAA could not be detected under SEM, it had an influence on different properties of the resulting membrane: swelling ratio and 5-FU permeability. This detail will be described below.

\subsection{Swelling ratio of the membrane}

Figs. 5 and 6 show the swelling ratio of EVAL and PAA/EVAL blended membranes prepared at 45 and $60^{\circ} \mathrm{C}$, respectively, in buffer solutions with different $\mathrm{pH}$ values at $37^{\circ} \mathrm{C}$. The swelling ratio was the maximum hydration degree

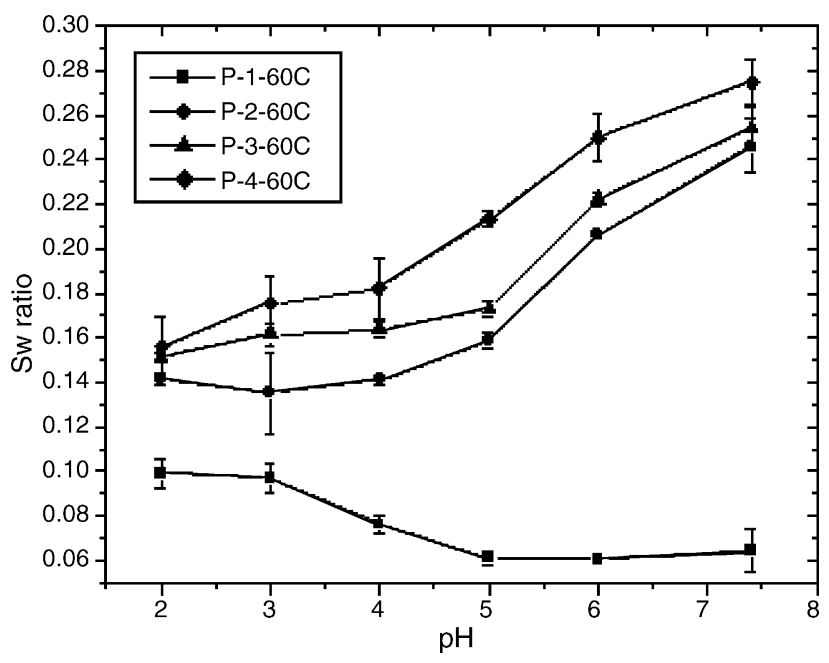

Fig. 6. Swelling ratio of EVAL and PAA/EVAL blended membranes prepared at $60^{\circ} \mathrm{C}$ in buffer solutions with different $\mathrm{pH}$ values at $37^{\circ} \mathrm{C}$. 
reached after immersion of three samples in an aqueous solution of a prescribed $\mathrm{pH}$. The water swelling characteristic was examined because it had a significant influence on drug permeation across the membrane. The swelling ratio of the membrane may be mainly determined by three factors, i.e. membrane preparation temperature, PAA content of the membranes and $\mathrm{pH}$ of buffer solution. As shown in Figs. 5 and 6, the swelling ratio of membranes prepared at $45^{\circ} \mathrm{C}$ was always greater than that of membranes prepared at $60^{\circ} \mathrm{C}$, which was consistent with the observation under SEM that membranes prepared at $45^{\circ} \mathrm{C}$ was not so dense as those prepared at $60^{\circ} \mathrm{C}$. In addition, the swelling ratio of membranes increased with the increase of PAA content. This is because PAA favors the uptake of water into the PAA phase of membrane; thus, the introduction of PAA into the membranes increased membrane swelling ratio. More remarkable is the $\mathrm{pH}$ dependence of the membrane swelling. Besides the swelling ratio of pure EVAL membranes decreased slightly with the increase in $\mathrm{pH}$, the swelling ratio of the blended membranes was greatly increased when the $\mathrm{pH}$ of buffer solution increased. This indicated that the PAA/EVAL blended membranes could provide different swelling ratio for drug delivery at different $\mathrm{pH}$ values.

\subsection{5-FU permeability across the membrane}

Figs. 7 and 8 show the time dependence of the cumulative amount of 5-FU permeation through EVAL and PAA/EVAL blended membranes prepared at 45 and $60^{\circ} \mathrm{C}$, respectively, at $\mathrm{pH} 2.0$ and 7.4. Basically, the permeation rate of 5-FU through all of the membranes increased with the increase of PAA content, which was consistent with the result that PAA could increase the swelling ratio of the blended membranes. When the data were evaluated based on membrane preparation temperature dependence, the permeation rate of 5-FU through the membranes prepared at $45^{\circ} \mathrm{C}$ was always greater than those prepared at $60{ }^{\circ} \mathrm{C}$, which was also consistent with the swelling measurement that membranes prepared at $45^{\circ} \mathrm{C}$ had higher swelling degree.

When the data were evaluated based on the $\mathrm{pH}$ of buffer solution, there was no significant difference for the cumulative amount of 5-FU in the first $24 \mathrm{~h}$ at $\mathrm{pH} 2.0$ and 7.4 (Fig. 7a and b) for membranes prepared at $45^{\circ} \mathrm{C}$. This indicates that PAA could increase the permeation rate of 5-FU through the blended membranes but could not further provide improved permeability of 5-FU in the acidic or neutral environment. Thus, PAA could not modify the EVAL membranes prepared at $45^{\circ} \mathrm{C}$ to result in the conversion of the membrane to be $\mathrm{pH}$-sensitive.

Now, 5-FU flux values are given to more clearly indicate the $\mathrm{pH}$ dependence of 5-FU permeability through the prepared membranes. Fig. 9 shows the 5-FU flux through EVAL and PAA/EVAL blended membranes at $\mathrm{pH} 2.0$ and 7.4. The 5-FU flux $(J)$ was obtained at time zero of Figs. 7 and 8 by using $J=V \Delta C / A \Delta t$, where $V$ is the volume of diffusion chamber, $\Delta C$ the drug concentration difference across the membrane, $A$ the membrane area and $\Delta t$ is the diffusion time. There was no clear difference for the 5-FU flux through the membranes prepared at $45^{\circ} \mathrm{C}$ between at pH 2.0 and 7.4 (Fig. 9a). Conversely, when membranes were prepared at $60^{\circ} \mathrm{C}$, the $\mathrm{pH}$-sensitive effect

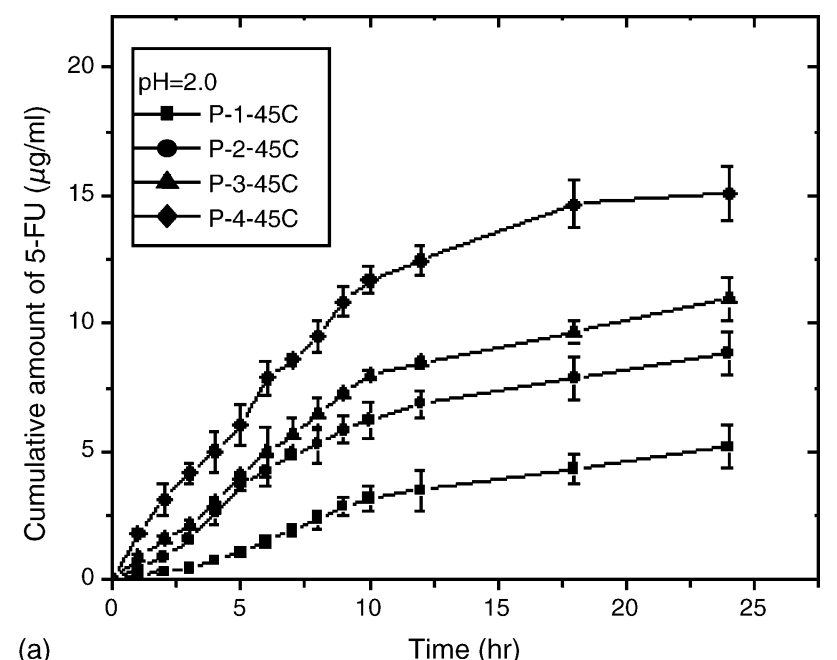

(a)

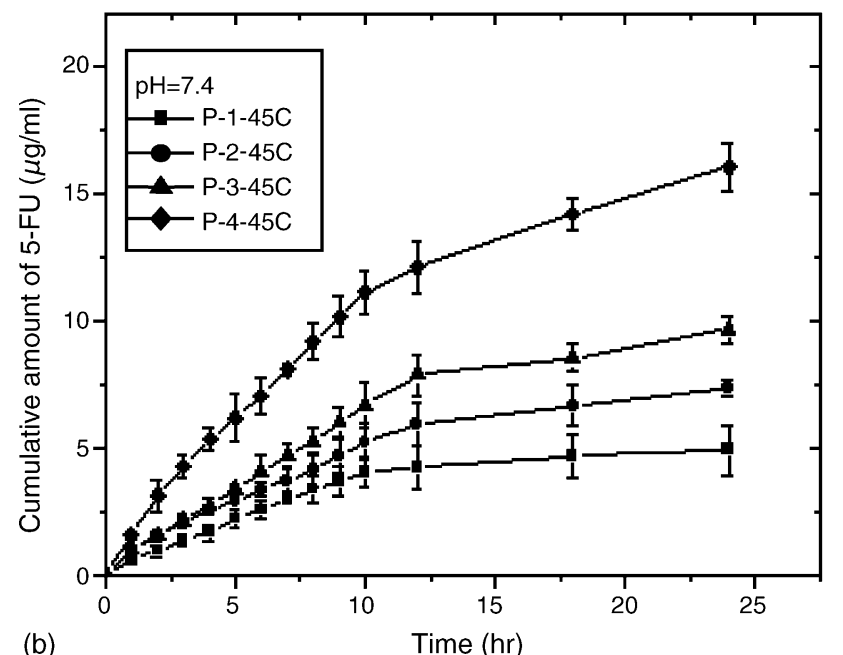

Fig. 7. Cumulative amount of 5-FU permeation through EVAL and PAA/EVAL blended membranes prepared at $45^{\circ} \mathrm{C}$ at (a) $\mathrm{pH} 2.0$ and (b) $\mathrm{pH}$ 7.4.

of PAA was significant, at each of the PAA/EVAL blended membranes studied (Fig. 9b). The 5-FU flux at $\mathrm{pH} 7.4$ was much higher than that at $\mathrm{pH} 2.0$. Therefore, there was much higher cumulative amounts of 5-FU permeation through the PAA/EVAL blended membranes at $\mathrm{pH} 7.4$ relative to at $\mathrm{pH} 2.0$ (Fig. $8 \mathrm{a}$ and b). Nearly, the cumulative amounts of 5-FU permeation through P-2-60C, P-3-60C and P-4-60C membranes after $24 \mathrm{~h}$ increased about 4.5-, 4.9- and 5.7-folds, respectively, for the $\mathrm{pH}$ value changed from 2.0 to 7.4. Such high cumulative amounts of 5-FU permeating across the PAA/EVAL blended membranes prepared at $60^{\circ} \mathrm{C}$ actually were comparable with membranes prepared at $45^{\circ} \mathrm{C}$. This indicates that the PAA/EVAL blended membranes prepared at $60{ }^{\circ} \mathrm{C}$ could provide $\mathrm{pH}$-selective permeability for 5-FU, which were low permeable for 5-FU at low $\mathrm{pH}$, but significantly improved the permeability of 5-FU by the increase of $\mathrm{pH}$ of the medium. The cumulative amount of 5-FU permeation through the EVAL membranes prepared at $60^{\circ} \mathrm{C}$ was conspicuously small at $\mathrm{pH} 2.0$ and 7.4. It is believed that dense membrane structure and without the addition of PAA led to the low permeability of 5-FU. 


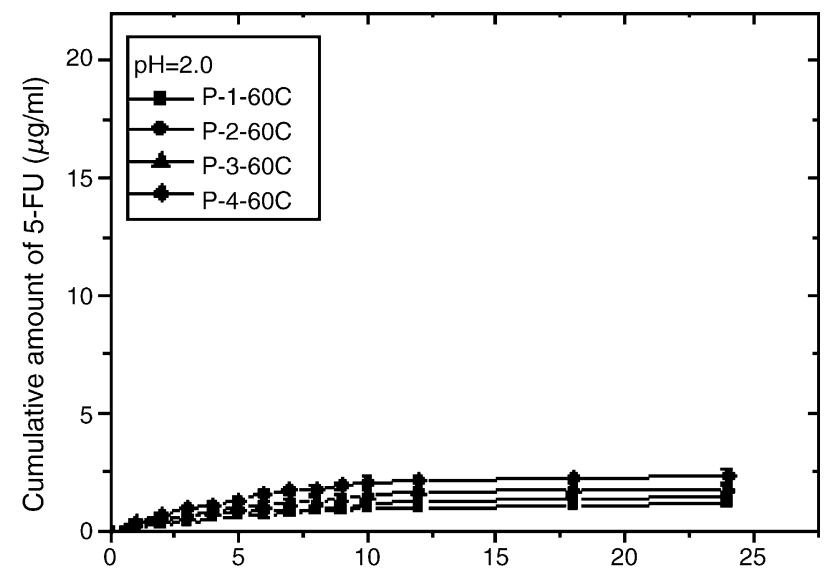

(a)

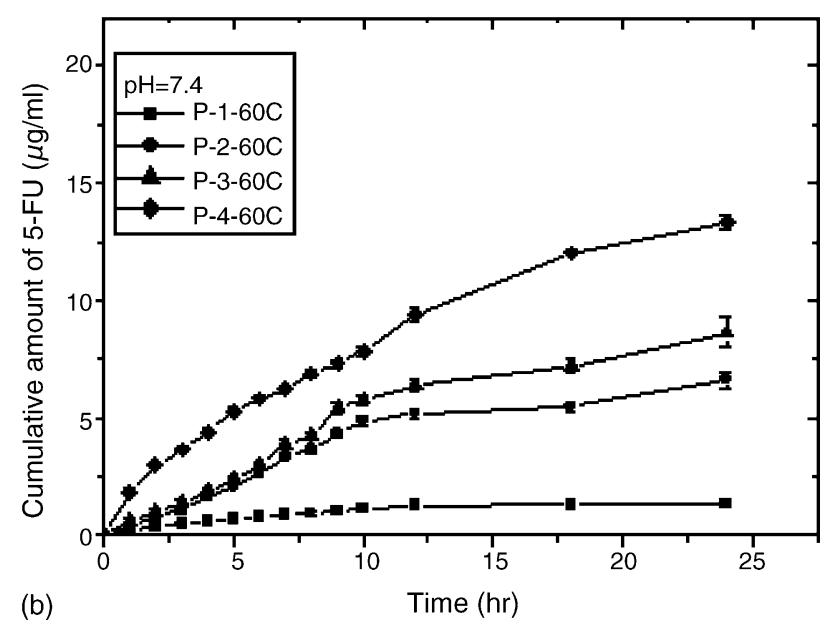

Fig. 8. Cumulative amount of 5-FU permeation through EVAL and PAA/EVAL blended membranes prepared at $60^{\circ} \mathrm{C}$ at (a) $\mathrm{pH} 2.0$ and (b) $\mathrm{pH} 7.4$.

Based on these experimental observations and the general assumptions, the rationale for the formation of $\mathrm{pH}$-sensitive membranes from adding PAA into the EVAL membrane would then be as follows: although the interaction of hydrogen bonding between PAA and EVAL declined the intensity of selfassociation in both polymers, the intensity of self-association of both polymers was still higher than that of inter-association between PAA and EVAL. Therefore, when the blended membranes were prepared at $60^{\circ} \mathrm{C}$, PAA and EVAL molecules would separately tend to aggregate to form the dense structure by virtue of a great number of molecular entanglements. At this time, PAA domain could be considered as hydrogel phase [28]. It is known a hydrogel can be characterized by its capacity to adsorb water. The water content in the equilibrium swelling affects the solute permeability across the hydrogel. Thus, it is reasonable to suggest most of 5-FU permeated through the PAA/EVAL blended membranes by way of water-swollen region of the PAA domain because the cumulative amount of 5-FU permeation through the pure EVAL membrane at $\mathrm{pH} 2.0$ and at $\mathrm{pH} 7.4$ appeared to be virtually the same and relatively low. In addition, the carboxylic acids of PAA can dissociate to carboxylate ions at $\mathrm{pH} 7.4$ to provide high charge density in the PAA domain. Therefore, the greater permeation rate of 5-FU at $\mathrm{pH} 7.4$ rather than at $\mathrm{pH} 2.0$
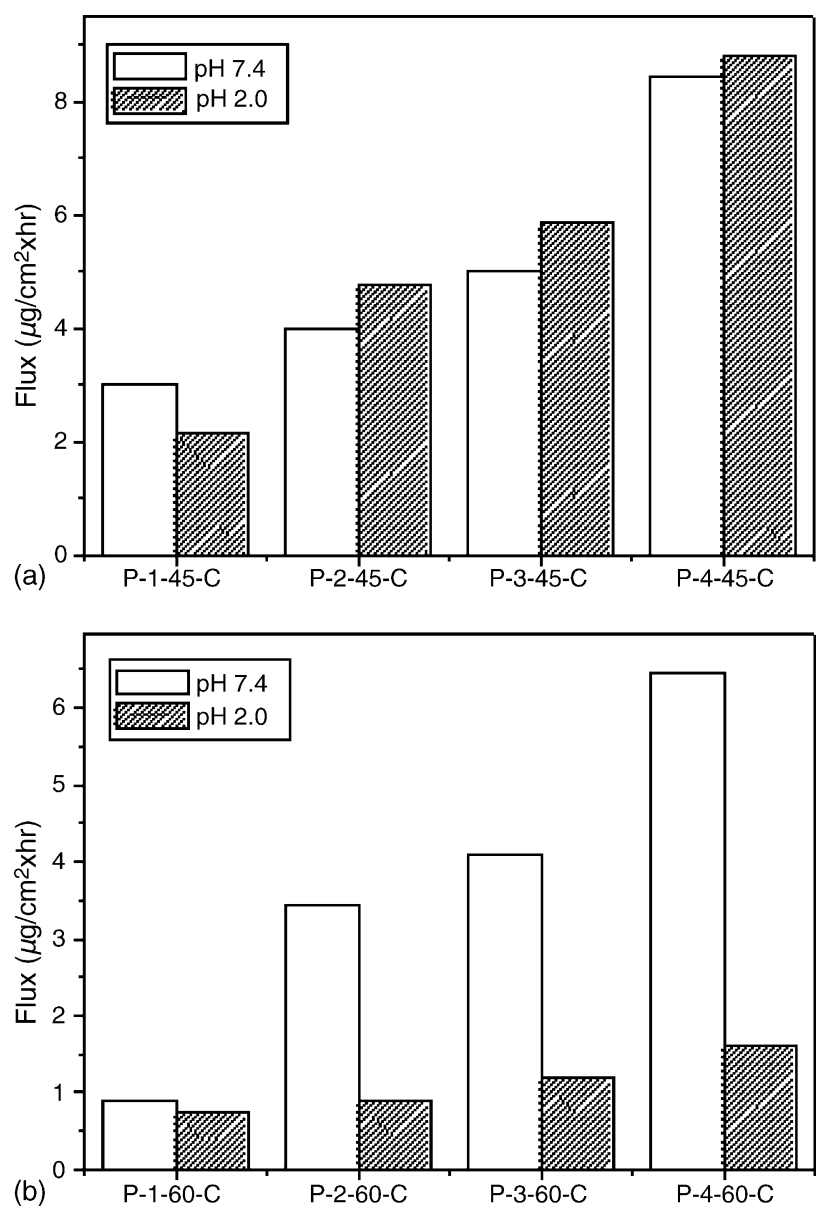

Fig. 9. Flux of 5-FU through EVAL and PAA/EVAL blended membranes prepared at (a) 45 and (b) $60^{\circ} \mathrm{C}$ at $\mathrm{pH} 2.0$ and 7.4.

was due to the electrical repulsion between adjacent carboxylate ions and a transition of compact coiled PAA chains to extended ones to swell PAA domain. Consequently, PAA/EVAL blended membranes may be considered as PAA hydrogel domains dispersed within the EVAL matrix and the mesh size of hydrogel phase is tight and compact at $\mathrm{pH} 2.0$ but is loose and diluted at $\mathrm{pH} 7.4$ [28], namely $\mathrm{pH}$-sensitive characteristic in the EVAL membrane was successfully created by blending with PAA. Furthermore, the fluorescein isothiocyanate-dextran with average molecular weight $40 \mathrm{~K}$ was used as the feed to evaluate the $\mathrm{pH}$ sensitive mesh size. The P-4-60C membrane was found to reject dextran at $\mathrm{pH}$ 7.4. This suggests that the available space for drug permeation through P-4-60C membrane was less than the size of dextran with average molecular weight $40 \mathrm{~K}$. Therefore, it is not surprised that these $\mathrm{pH}$-sensitive phases were beyond the observable sensitivity of the SEM and acted as the access for the transport of nano-scale solute through the blended membranes.

On the other hand, PAA domain contained in the blended membrane prepared at $45^{\circ} \mathrm{C}$ did not affect the permeation rate of 5-FU at different $\mathrm{pH}$ values. This is because the membranes themselves were not so dense that even the swelling ratio of $\mathrm{P}$ $1-45 \mathrm{C}$ membranes at $\mathrm{pH} 2.0$ was very close to that of P-4-60C membrane prepared at $\mathrm{pH} 7.4$ (Fig. 6). The other possible origin of the enhancement of 5-FU permeability across the PAA/EVAL 


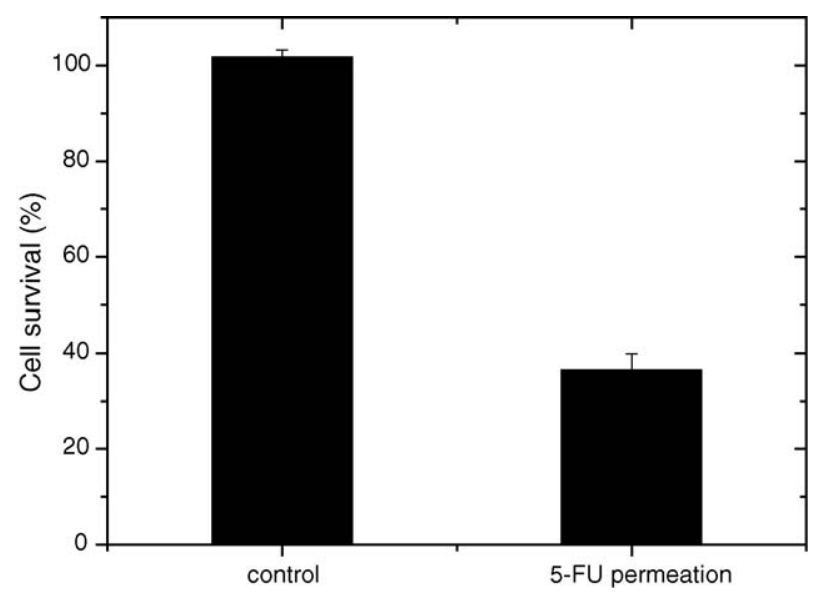

Fig. 10. Viability of Caco-2 cells exposed to 5-FU, separated by the P-4-60C membrane in the diffusion cell at $\mathrm{pH} 7.4$ for $24 \mathrm{~h}$.

blended membranes prepared at $60^{\circ} \mathrm{C}$ was that the 5-FU partition in the membrane increased for the $\mathrm{pH}$ value changed from 2.0 to 7.4. However, the blended process in this study did not significantly change the permeation of 5-FU for the membranes prepared at $45^{\circ} \mathrm{C}$. Therefore, the enhancement of 5-FU permeability in the blended membranes at $\mathrm{pH} 7.4$ could not be ascribed to the higher partition coefficient of 5-FU in the PAA hydrogel phases. Consequently, the $\mathrm{pH}$-sensitive characteristic of PAA domains would be applicable only to the membrane exhibit a relatively dense structure.

\subsection{Viability of Caco-2 cells}

In order to simulate the in vivo condition, Caco- 2 cells and 5-FU were separated by the P-4-60C membrane in the diffusion cell at $\mathrm{pH}$ 7.4. The toxicity of 5-FU permeating through the membrane toward Caco- 2 cells was evaluated by the MTT assay following $24 \mathrm{~h}$ of permeation at $37^{\circ} \mathrm{C}$. Compared to control cells, cell viability was dramatically decreased to $36 \pm 3.4 \%$ in the presence of permeated 5-FU (Fig. 10). This finding indicated that Caco-2 cells were indeed damaged for 5-FU permeation though the P-4-60C membrane at $\mathrm{pH}$ 7.4. Therefore, such a diffusion cell combining with cell culture can be extensively applied to other studies for drug delivery in vitro.

\section{Conclusion}

In the present study, the non-pH-sensitive EVAL membrane prepared at $60^{\circ} \mathrm{C}$ could be converted to $\mathrm{pH}$-sensitive by adding a small amount of PAA. According to the FTIR spectra and swelling measurements, it is suggested that PAA domains dispersed within the EVAL matrix and PAA plays an important role on the $\mathrm{pH}$-sensitivity of the blended membranes. The study also revealed that 5-FU separated by the blended membranes still exhibited cytotoxicitiy toward Caco-2 cells at $\mathrm{pH}$ 7.4 Thus, the PAA/EVAL blended membrane is a potential material for the specific delivery of 5-FU to the colon for local treatment of $\mathrm{CRC}$ in the future clinical application.

\section{Acknowledgment}

The authors thank the National Science Council of the Republic of China for their financial support.

\section{References}

[1] H.M. Pinedo, G.F.J. Peters, Fluorouracil-biochemistry and pharmacology, J. Clin. Oncol. 6 (1988) 1653.

[2] W.H. Isacoffand, K. Borud, Chemotherapy for the treatment of patients with metastatic colorectal cancer: an overview, World J. Surg. 21 (1997) 748.

[3] P.J. Loehrer, S. Turner, P. Kubilis, S. Hui, J. Correa, R. Ansari, D. Stephens, R. Woodburn, S. Meyer, A prospective randomized trial of fluorouracil versus fluorouracil plus cisplatin in the treatment of metastatic colorectal-cancer-a hoosier oncology group trial, J. Clin. Oncol. 6 (1988) 642.

[4] M.A. Poon, M.J. Oconnell, C.G. Moertel, H.S. Wieand, S.A. Cullinan, L.K. Everson, J.E. Krook, J.A. Mailliard, J.A. Laurie, L.K. Tschetter, M. Wiesenfeld, Biochemical modulation of fluorouracilevidence of significant improvement of survival and quality of life in patients with advanced colorectal-carcinoma, J. Clin. Oncol. 7 (1989) 1407.

[5] G. Milano, P. Roman, R. Khater, M. Frenay, N. Renee, M. Namer, Dose versus pharmacokinetics for predicting tolerance to 5-day continuous infusion of 5-FU, Int. J. Cancer 41 (1988) 537

[6] H. Bleiberg, Colorectal cancer-is there an alternative to 5-FU? Eur. J. Cancer 33 (1997) 536.

[7] F.H. Lin, Y.H. Lee, C.H. Jian, J.M. Wong, M.J. Shieh, C.Y. Wang, A study of purified montmorillonite intercalated with 5-fluorouracil as drug carrier, Biomaterials 23 (2002) 1981.

[8] R.J. Mrsny, The colon as a site for drug delivery, J. Control. Release 22 (1992) 15.

[9] A. Rubinstein, Approaches and opportunities in colon-specific drugdelivery, Crit. Rev. Ther. Drug Carr. Syst. 12 (1995) 101.

[10] P.J. Watts, L. Illum, Colonic drug delivery, Drug Dev. Ind. Pharmacol. 23 (1997) 893.

[11] E.O. Akala, P. Kopeckova, J. Kopecek, Novel pH-sensitive hydrogels with adjustable swelling kinetics, Biomaterials 19 (1998) 1037.

[12] M.D. Blanco, O. Garcia, R.M. Trigo, J.M. Teijon, I. Katime, 5Fluorouracil release from copolymeric hydrogels of itaconic acid monoester, Biomaterials 17 (1996) 1061.

[13] H. Brondsted, C. Andersen, L. Hovgaard, Crosslinked dextran-a new capsule material for colon targeting of drugs, J. Control. Release 53 (1998) 7.

[14] M. Changez, K. Burugapalli, V. Koul, V. Choudhary, The effect of composition of poly(acrylic acid)-gelatin hydrogel on gentamicin sulphate release: in vitro, Biomaterials 24 (2003) 527.

[15] M.J. Shieh, P.S. Lai, T.H. Young, 5-Aminosalicylic acid permeability enhancement by a pH-sensitive EVAL membrane, J. Membr. Sci. 204 (2002) 237.

[16] B. Vazquez, M. Gurruchaga, I. Goni, E. Narvarte, J.S. Roman, A pH-sensitive hydrogel based on poly(ethoxy triethylene glycol monomethacrylate), Polymer 36 (1995) 3327.

[17] Y. Sakurada, A. Sueoka, M. Kawahashi, Blood purification device using membranes derived from poly(vinyl-alcohol) and copolymer of ethylene and vinyl alcohol, Polymer J. 19 (1987) 501.

[18] D.T. Lin, L.P. Cheng, Y.J. Kang, L.W. Chen, T.H. Young, Effects of precipitation conditions on the membrane morphology and permeation characteristics, J. Membr. Sci. 140 (1998) 185.

[19] T.H. Young, W.Y. Chuang, C.W. Wei, C.Y. Tang, Investigation of the drug distribution and release characteristics from particulate membranes, J. Membr. Sci. 191 (2001) 199.

[20] T.H. Young, W.W. Hu, Covalent bonding of lysine to EVAL membrane surface to improve survival of cultured cerebellar granule neurons, Biomaterials 24 (2003) 1477. 
[21] T.H. Young, C.W. Lin, L.P. Cheng, C.C. Hsieh, Preparation of EVAL membranes with smooth and particulate morphologies for neuronal culture, Biomaterials 22 (2001) 1771.

[22] T.H. Young, J.H. Huang, S.H. Hung, J.P. Hsu, The role of cell density in the survival of cultured cerebellar granule neurons, J. Biomed. Mater. Res. 52 (2000) 748.

[23] R.L. Luo, T.H. Young, Y.M. Sun, Structure formation and characterization of EVAL membranes with cosolvent of isopropanol and water, Polymer 44 (2003) 157.

[24] K.A. Smith, C.K. Colton, E.W. Merrill, L.B. Evans, Evans convective transport in a batch dialyzer. Determination of the true membrane permeability from a single measurement, AIChE Symp. Ser. 64 (1968) 45.
[25] T. Mosmann, Rapid colorimetric assay for cellular growth and survivalapplication to proliferation and cyto-toxicity assays, J. Immunol. Methods 65 (1983) 55.

[26] I. Katime, L.G. Parada, E. Meaurio, L.C. Cesteros, $\operatorname{Poly}(N, N$ dimethylacrylamide)/copolymers of vinyl alcohol blends: effect of the comonomer, Polymer 41 (2000) 1369.

[27] J. Dong, Y. Ozaki, K. Nakashima, Infrared, Raman, and near-infrared spectroscopic evidence for the coexistence of various hydrogen-bond forms in poly(acrylic acid), Macromolecules 30 (1997) 11117.

[28] N.A. Peppas, P. Buresa, W. Leobandunga, H. Ichikawab, Hydrogels in pharmaceutical formulations, Eur. J. Pharm. Biopharm. 50 (2000) 27. 